\title{
Spinach production in cocopeat: effects of soil block number and the number of emitters per styrofoam box on plant growth, nitrate concentration, and antioxidant activity
}

\author{
R.M.A. Machado ${ }^{1,2, a}$, I. Alves-Pereira ${ }^{1,3}$ and R.M.A. Ferreira ${ }^{1,3}$ \\ ${ }^{1}$ ICAAM - Instituto de Ciências Agrárias e Ambientais Mediterrânicas, Universidade de Évora, Évora, Portugal; \\ 2Departamento de Fitotecnia, Universidade de Évora, Évora, Portugal; ${ }^{3}$ Departamento de Química, Escola de \\ Ciência Tecnologia, Universidade de Évora, Évora, Portugal.
}

\begin{abstract}
Currently, the interest in using cocopeat or coir dust alone as a growing medium to produce leafy vegetables has increased. This research aimed to evaluate the effects of soil block number and of the number of emitters per styrofoam box on plant growth, nitrate $\left(\mathrm{NO}_{3}{ }^{-}\right.$) concentration, and antioxidant activity in spinach (Spinacia oleracea $\mathrm{L}$. 'Manatee') cultivated in cocopeat. The experiment was carried out with four treatments, 8 and 14 soil blocks (160 and 280 plants $\mathrm{m}^{-2}$ ) and 4 and 8 emitters per styrofoam box. The crop was irrigated and fertigated daily with a complete nutrient solution. The yield $\left(\mathrm{kg} \mathrm{m}^{-2}\right)$ was increased significantly with soil block number and with the number of the emitters by styrofoam box, reaching $5.4 \mathrm{~kg} \mathrm{~m}^{-2}$ in the treatment with 14 soil blocks ( 280 plants $\mathrm{m}^{-2}$ ) and 8 emitters. Soil block number had no effect on shoot dry weight plant $^{-1}$, leaf-blade and petiole nitrate concentration and total phenols content. The increase in the number of emitters per styrofoam box decreased leafblade total phenol sand leaf-blade antioxidant activity. Ferric-reducing antioxidant activity (FRAP) values in the leaf-blade treatments with four emitters ranged from 7.3 to $9.7 \mathrm{mg}$ eq. trolox $\mathrm{g}^{-1} \mathrm{FW}$. The leaf-blade phenols content and FRAP values were $\approx \mathbf{8}$ and 9 times higher than in the petioles, respectively. These results indicate that cocopeat is a very suitable growing medium for spinach production.
\end{abstract}

Keywords: Spinacia oleracea, soilless culture systems,soil block, yield, nitrogen, phenol, FRAP

\section{INTRODUCTION}

Cocopeat or coir dust is a bio-degradable and renewable resource with some chemical and hydrological features similar to peat and higher durability, which can reduce or replace peat as a growing medium for soilless cultivation. Spinach yield was greater when plants were grown in peat than the mixed substrate or the coir (Barcelos et al., 2016). However, spinach yield and leaf-blade nitrate concentration could be affected by cultural techniques (Machado et al., 2019). The increase in the number of water emission points over the substrate increase the yield and reduce the leaf-blade nitrate concentration (Machado et al., 2019). Cocopeat has a high water holding capacity which may cause poor air-water relationship, leading to low aeration within the medium, thus affecting the oxygen diffusion to the roots (Awang et al., 2009). The increase in the number of water emission points over the substrate can reduce this constraint because it reduces the duration of each irrigation event, promotes a greater homogeneity of the moisture and a higher degree of water retention in the substrate (Valdés et al., 2014) affecting ion distribution in the growing medium, which may influence yield and quality. In Portugal, the use of soil blocked spinach seedlings in spinach production is increasing. The objective of this study was to evaluate the effect of the soil block number and the number of emitters per styrofoam box on plant growth, nitrate $\left(\mathrm{NO}_{3}{ }^{-}\right)$concentration and antioxidant activity in spinach cultivated in cocopeat.

aE-mail: rmam@uevora.pt 